International Journal of Soft Computing 5 (4): 185-193, 2010

ISSN: $1816-9503$

(C) Medwell Journals, 2010

\title{
Fuzzy Based Multi Criteria Contingency Ranking for Voltage Stability Assessment
}

\author{
M. Kowsalya, K.K. Ray, Ranjeet Kumar and Raunak Rastogi \\ School of Electrical Engineering, VIT University, Vellore, Tamil Nadu, India
}

\begin{abstract}
Contingency screening and ranking is one of the important components of on-line system security assessment which is done with the help of various computer software's which employ the iterative load flow methods. The objective of this contingency screening and ranking is to quickly and accurately select a short list of critical contingencies from large potential contingencies and rank them according to their severity. To maintain security against voltage collapse, it is desirable to estimate the effect of the contingencies on the voltage stability. In general terms, the proposed procedure consists of obtaining the operating state and computing performance indices for each contingency of a predefined list. The contingencies are then ranked according to their performance indices. This study presents fuzzy approach to combine ranking of the performance indices and a new rank list is prepared. The proposed approach is tested on IEEE-14 bus test system and practical Indian 75-bus test system.
\end{abstract}

Key words: Voltage stability index, fuzzy sets, contingency ranking, performance indices, screening, iterative

\section{INTRODUCTION}

Electric Power Systems (EPS) have become very complex from the operation, control and stability maintenance standpoints. The voltage stability problem deserves special attention, since power systems have been operating dangerously close to their stability limits. Voltage collapse and energy rationing occurrences have been reported worldwide.

Special care with transmission capacity expansion and the development of efficient operation techniques to best use the system's capabilities is crucial. The power industry restructuring process has introduced a number of factors that have increased the possible sources of system disturbances, leading to a less robust, more unpredictable system as far as the operation is concerned (Morison et al., 2004).

The lack of new transmission facilities, cutbacks in system maintenance, research force downsizing, unpredicted power flow patterns, just to name a few are some of the important factors that affect the security of power systems. The mainstream philosophy of the restructured sector is to minimize investments, minimize costs and maximize the equipment's utilization. The regulatory agencies usually define minimum voltage stability security margins for both normal operating conditions and contingency situations. Under normal operating conditions, the minimum margin should be a bit larger depending on the demand. Figure 1 shows the idea

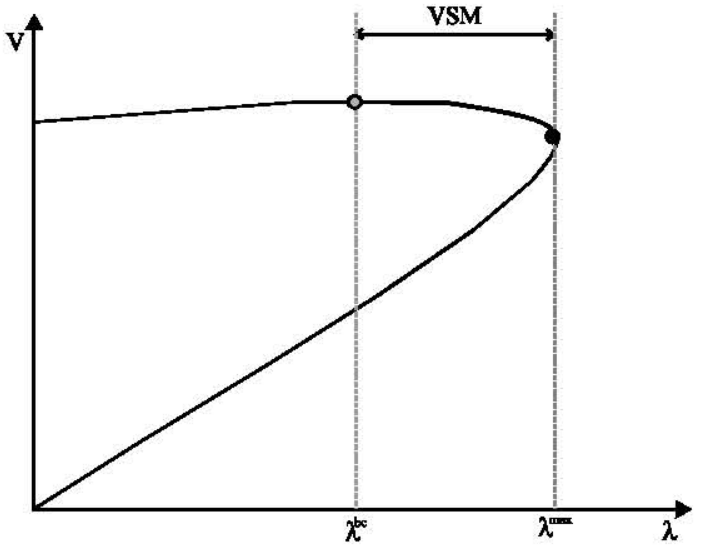

Fig. 1: Illustration of Voltage Stability Margin (VSM)

of the Voltage Stability Margin (VSM) in a very simple way based on the well-known PV curve. Consider the load flow equations given by:

$$
\begin{aligned}
& \lambda P_{s}^{k}-P_{c}^{k}(\theta, V)=0, \text { for } P Q, P V \text { buses and } \\
& \lambda Q_{s}^{k}-Q_{c}^{k}(\theta, V)=0, \text { for } P Q \text { buses }
\end{aligned}
$$

where, superscripts $\mathrm{s}$ and $\mathrm{c}$ stand for scheduled (generation minus consumption) and calculated quantities. In this study a constant power factor model is used for the loads. None the less, the inclusion of voltage dependent load models is straightforward. $\lambda^{\text {bc }}$ and $\lambda^{\text {max }}$ correspond, respectively to the current and the maximum

Corresponding Author: M. Kowsalya, School of Electrical Engineering, VIT University, Vellore, Tamil Nadu, India 


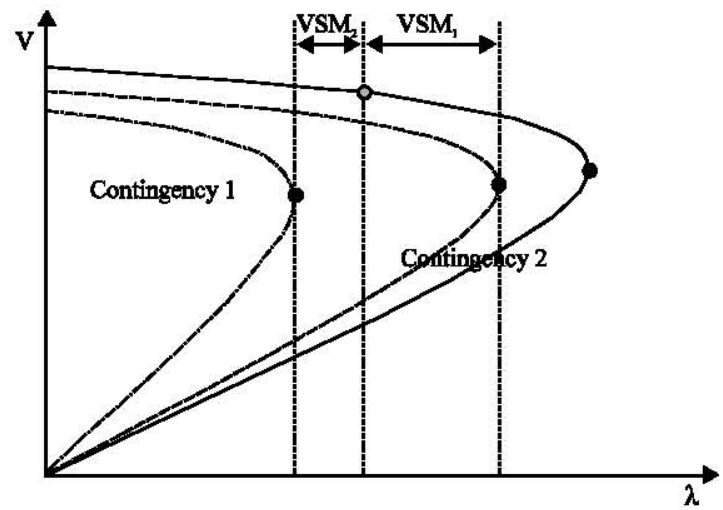

Fig. 2: Impact of contingencies on VSM

loading factors both for normal operating conditions (base case). VSM is computed from both loading levels, being a measure of the distance between them. For instance, VSM can be given by:

$$
\operatorname{VSM}=\left(\frac{\lambda^{\max }}{\lambda^{b c}}-1\right) \times 100
$$

The occurrence of contingencies results in variation of the VSM as shown in Fig. 2. Contingency 1 results in a smaller VSM as compared to the base case condition. Contingency 2 presents a more severe impact on VSM since its post-contingency maximum loading is less than the base case loading. This constitutes an infeasible contingency case. Of course this analysis is valid in case the load and generation patterns and control settings remain unchanged after the contingency occurs. A well-accepted contingency analysis procedure is based on splitting the process in different stages. The first stage is usually referred to as contingency ranking and contingencies from a predefined list are analyzed and ranked by using a simple, computationally fast method. Then, the top-ranked (most severe) contingencies are selected and analyzed in a latter stage now using more complete, powerful and accurate methods. This stage is usually referred to as contingency analysis or evaluation. For instance, the voltage stability condition of the most severe contingencies may be evaluated by continuation methods (Ajjarapu and Christy, 1992). Finally, preventive and/or corrective control strategies must be obtained to deal with contingencies that result in insecure or emergency operating situations. The procedure just described has been discussed by Stott et al. (1987) for ranking and analyzing contingencies for MW flow overloads and voltage magnitude violations. This study tackles the contingency ranking problem that is the one of correctly ranking contingencies regarding their impacts on
VSM. Contingencies with the smallest VSM are the most severe and ranked at the top of the list. The evaluation of the impact of contingencies on the VSM has been dealt with in several research works found in the literature. A crucial point related to this problem is that a proposed ranking method must be efficient from the computational effort standpoint while keeping acceptable accuracy. Also, it should be suited for use in many power system analysis process environments, from operation planning to real time operation. Finally an appropriate treatment for the infeasible contingency cases is also proposed.

Many research works on contingency ranking for voltage stability can be found in the literature assume that the operating state at base case is known for both normal operation and maximum loading condition. The idea here is to propose a method for ranking contingencies based on information from the base case and the postcontingency operating states. Thus, only one load flow is required for each contingency. Therefore, the method is intended to be computationally fast and suited for real time operation application where decisions must be taken within a small time frame. The ranking method is based on the computation of performance indices for each contingency. In their turn, the performance indices are based on the post-contingency operating state. Some of these indices include the computation of voltage stability indices which are in turn obtained from the equations of power flows through branches (transmission lines and transformers). These voltage stability indices are multiplied by weight factors which are based on the outage branch pre-contingency apparent power flow and on the voltage (magnitude and phase angle) variations.

The high order performance index methods have drawback of more computation time. The performance index methods also have masking phenomena. Many attempts were made to use fuzzy logic techniques in contingency analysis (Hsu and Kuo, 1992; Lo and Abdelall, 2000; Ozdemir and Singh, 2001) which is based on separate consideration of state variables like line flows and voltage deviation. But it may give many mis-rankings if we take only one variable based rank list. In the study a fuzzy logic based combined rank list is developed considering the performance indices for each contingency for different single outage cases. They are combined with other performance indices based on the relationship between the branch current and maximum apparent power flows.

\section{THEORETICAL BACK GROUND}

Voltage stability index: Figure 3 shows a branch that connects the branch $i$ and $j$. The real and reactive power flows through branch $i-j$ are: 


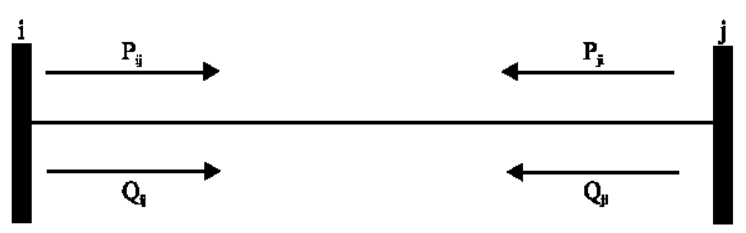

Fig. 3: Branch i-j of a power system

$$
\begin{gathered}
P_{i j}=\left(V_{j}\right)^{2} g_{i j}-\left(a_{i j} V_{i}\right) V_{j}\left[Y_{i j} \cos \left(\phi+\theta_{i j}^{e q}\right)\right] \\
Q_{i j}=-\left(V_{j}\right)^{2}\left(b_{i j}+b_{i j}^{\text {sh }}\right)+\left(a_{i j} V_{i}\right) V_{j}\left[Y_{i j} \sin \left(\phi+\theta_{i j}^{e q}\right)\right]
\end{gathered}
$$

where, $\theta^{\text {eq }}{ }_{i j}=\theta_{i}-\theta_{j}+\phi_{i j}$ is the angle spread at branch $i-j$. In the case of a transmission line; $\mathrm{a}_{\mathrm{ij}}=1, \phi_{\mathrm{ij}}=0$. For transformer; $\mathrm{b}_{\mathrm{ij}}^{\mathrm{sh}}=0, \phi_{\mathrm{ij}}=0$. For pure phase shifters; $\mathrm{b}_{\mathrm{ij}}^{\mathrm{sh}}=0, \mathrm{a}_{\mathrm{ij}}=1=$ For phase shifters; $\mathrm{b}_{\mathrm{ij}}^{\mathrm{sh}}=0$. From Eq. 3 and 4 one gets:

$$
\mathrm{a}\left(\mathrm{V}_{\mathrm{j}}\right)^{4}+\mathrm{b}\left(\mathrm{V}_{\mathrm{j}}\right)^{2}+\mathrm{c}=0
$$

Where:

$$
\begin{aligned}
& \mathrm{a}=\left\lfloor\left(\mathrm{g}_{\mathrm{ij}}\right)^{2}+\left(\mathrm{b}_{\mathrm{ij}}+\mathrm{b}_{\mathrm{ij}}^{\mathrm{sh}}\right)^{2}\right\rfloor \\
& \mathrm{b}=\left\{\left[\left(\mathrm{b}_{\mathrm{ij}}+\mathrm{b}_{\mathrm{ij}}^{\mathrm{sh}}\right)\right] \mathrm{Q}_{\mathrm{ij}}-2\left(\mathrm{~g}_{\mathrm{ij}}\right) \mathrm{P}_{\mathrm{ji}}-\left[\mathrm{y}_{\mathrm{ij}}\left(\mathrm{a}_{\mathrm{ij}} \mathrm{V}_{\mathrm{i}}\right)\right]^{2}\right\} \text { and } \\
& \mathrm{c}=\left(\mathrm{P}_{\mathrm{ij}}\right)^{2}+\left(\mathrm{Q}_{\mathrm{ij}}\right)^{2}
\end{aligned}
$$

Equation 5 has real solutions when $b^{2}-4 a c \geq 0$; Finally, a voltage stability index is defined as follows:

$$
\begin{aligned}
& \operatorname{VSI}_{\mathrm{ij}}=\mathrm{b}^{2}-4 \mathrm{ac}=\left\{\left[\left(\mathrm{b}_{\mathrm{ij}}+\mathrm{b}_{\mathrm{ij}}^{\mathrm{sh}}\right)\right] \mathrm{Q}_{\mathrm{ij}}-2\left(\mathrm{~g}_{\mathrm{ij}}\right) \mathrm{P}_{\mathrm{ji}}-\left[\mathrm{y}_{\mathrm{ij}}\left(\mathrm{a}_{\mathrm{ij}} \mathrm{V}_{\mathrm{i}}\right)\right]^{2}\right\}^{2} \\
& -4\left[\left(\mathrm{~g}_{\mathrm{ij}}\right)^{2}+\left(\mathrm{b}_{\mathrm{ij}}+\mathrm{b}_{\mathrm{ij}}^{\mathrm{sh}}\right)^{2}\right]\left[\left(\mathrm{P}_{\mathrm{ij}}\right)^{2}+\left(\mathrm{Q}_{\mathrm{ij}}\right)^{2}\right] \geq 0
\end{aligned}
$$

VSI tends to zero as the load increases and the system approaches its voltage stability limit. Even though VSI was originally derived for a radial system, it will be meshed systems since it provides a good approximation of the system's voltage stability condition.

Performance indices: One of the main points discussed in this study is related to the definition of appropriate Performance Indices (PI) that reflect the actual postcontingency operating conditions regarding voltage stability.

Five PI have been chosen and were used in the proposed ranking method. The choice of using more than one PI is based on the following ideas. First, no voltage stability index alone is able to reflect the actual post-contingency VSM in an accurate way, due to the nonlinearities of the problem. All voltage stability indices, VSI included present some degree of inaccuracy due to the simplified assumptions they are based on. Therefore, it is expected that a PI defined in terms of voltage stability indices would also carry some degree of inaccuracy. It is important that the voltage stability index be associated to other quantities to compensate for such inaccuracies and minimize errors. Secondly, it was also found that each definition of a PI favors the identification of certain severe contingencies.

One of the contributions of this study is to show that each one of the different PI may be able to identify a number of severe contingencies and the union of the PI may result in almost all severe contingencies identified. The definition of PI and their association to other quantities were based on exhaustive tests. In this study, the following five performance indices were defined:

$$
\begin{aligned}
& \mathrm{PI}_{1}=\frac{\mathrm{VSI}^{\min }}{\alpha_{1}} ; \mathrm{PI}_{2}=\frac{\mathrm{VSI}^{\min }}{\alpha_{2}} ; \mathrm{PI}_{3}=\frac{\mathrm{VSI}^{\min }}{\alpha_{3}} ; \\
& \mathrm{PI}_{4}=\max \left(\frac{\mathrm{s}_{1}}{\mathrm{~s}_{1}^{\max }}\right) \text { and } \mathrm{PI}_{5}=\operatorname{avrg}\left(\frac{\mathrm{s}_{1}}{\mathrm{~s}_{1}^{\max }}\right)
\end{aligned}
$$

Weighting factors $\mathrm{i}$ were added to the first three performance indices to improve their accuracy. $\mathrm{VSI}_{\min }$ is the smallest post-contingency voltage stability index among the branches connected to the bus with the smallest base case voltage magnitude.

Weight $\alpha_{1}$ is the base case apparent power through outage branch $\mathrm{km}$. Weight $\alpha_{2}$ is the largest nodal phase angle variation from the base case to the contingency case.

Weight $\alpha_{3}$ is the largest nodal voltage magnitude variation from the base case to the contingency case. Note that factors $i$ are based on relevant system physical quantities and their variations are closely related to the voltage stability phenomenon. $\mathrm{S}_{\max }^{1}$ is calculated by:

$$
\mathrm{S}_{1}^{\max }=\frac{\mathrm{V}_{\mathrm{i}}^{2}}{4 \mathrm{Z}_{\mathrm{R}} \cos ^{2}(\gamma-\phi) / 2}
$$

where, branch 1 connects buses $i$ and $j$ and $\phi=\left\langle\left(V^{2} / S_{i j}^{*}\right)\right.$ (Albuquerque and Castro, 2003). Obviously, subscript 1 represents all branches in the system but the outage branch $\mathrm{km}$.

\section{PROPOSED FUZZY MODEL FOR COMBINED RANKING}

The contingencies causing line flow overloads may not necessarily cause bus voltage problems (Ozdemir and Singh, 2001) and vice versa, line flow problems and 


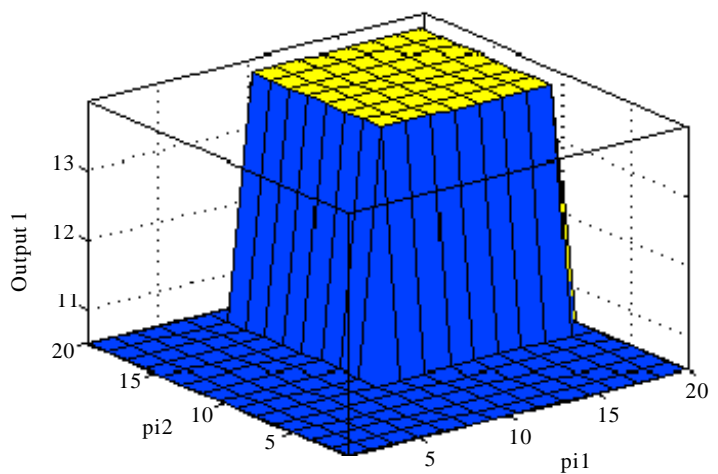

Fig. 4: Fuzzy surface of proposed model for IEEE-14 bus system

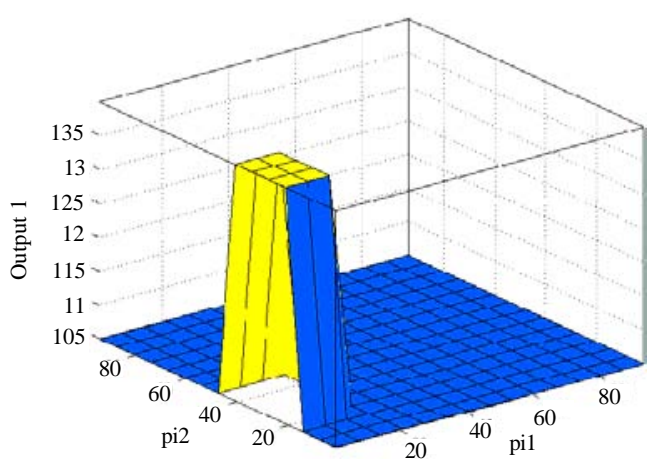

Fig. 5: Fuzzy surface of proposed model for practical indian 75 bus system

voltage limit violations problems must be dealt separately by associated performance indices. In the proposed approach, a new method is proposed to combine the five different rankings using fuzzy inference.

In this method five rankings are taken as inputs to the fuzzy tool box (available in MATLAB) and fuzzy co-efficient are generated based on some predefined if-then rules as a output. The fuzzy model used in this approach is tested in MATLAB 7.0 Fuzzy tool box.

Fuzzy Interference Structure (FIS) for combined performance indices ranking: The FIS structure given below is tested in MATLAB 7.0. Fuzzy Toolbox. Figure 4 shows the fuzzy surface of the proposed model for the IEEE-14 bus system.

Type: Mamdani, No. of inputs: 5, No. of outputs: 1, No. of rules: 7 and Method $=\min$ Or Method $=\max , \operatorname{Imp}$ Method $=\min$, Agg Method $=\max$, Defuzzification Method $=$ centroid.

Figure 5 shows the fuzzy surface of the proposed model for the practical Indian 75-bus system. For practical Indian-75 bus system. Type: Mamdani, No. of inputs: 5 ,

\begin{tabular}{|c|c|c|c|c|c|c|c|}
\hline $\begin{array}{l}\text { Rul } \\
\text { no. }\end{array}$ & $\mathrm{PI}_{1}$ & $\mathrm{PI}_{2}$ & $\mathrm{PI}_{3}$ & $\mathrm{PI}_{4}$ & $\mathrm{PI}_{5}$ & $\mathrm{~N}$ & $\begin{array}{l}\text { Fuzzy rank } \\
\text { coefficient }\end{array}$ \\
\hline 1 & High & High & High & High & High & High & High \\
\hline 2 & High & low & Low & Moderate & High & High & High \\
\hline 3 & High & Moderate & Low & High & High & \multicolumn{2}{|c|}{ Moderate High } \\
\hline 4 & Moderate & Low & Low & Moderate & Moderate & Low & Moderate \\
\hline 5 & Moderate & Low & Low & Low & Low & Low & Low \\
\hline 6 & High & High & High & High & High & \multicolumn{2}{|c|}{ Moderate High } \\
\hline 7 & Low & Low & Low & \multicolumn{4}{|c|}{ Moderate Moderate Moderate Low } \\
\hline 8 & Low & Low & Low & Low & Low & Low & Low \\
\hline 9 & Low & Low & Low & Moderate & Moderate & e High & Moderate \\
\hline 10 & Low & Moderate & Moderate & Low & Low & Low & Low \\
\hline 11 & Moderate & High & High & Moderate & Low & Low & Moderate \\
\hline 12 & Moderate & High & High & Moderate & Moderate & High & Moderate \\
\hline 13 & Low & Low & Moderat & Low & Low & Moderat & te Low \\
\hline
\end{tabular}

No. of outputs: 1, No. of rules: 17 and Method $=\min$, OrMethod $=\max$, ImpMethod $=\min$, AggMethod $=\max$, Defuzzification Method $=$ centroid .

Fuzzy membership values: Fuzzy sets for the combined contingency ranking inputs are the performance indices to the contingency ranking.

Here the membership functions for all the linguistic terms are taken as triangular function. The values are shown in the following Table 1 .

The developed fuzzy interference matrix fro the IEEE-14 bus system consists of seven rules and is shown in Table 1. Figure 6 shows the interface fuzzy membership value for the IEEE-14 bus system.

Fuzzy IF-THEN rules: The output and input membership functions to evaluate the severity of a post-contingent quality divided into three categories using Fuzzy set notation: low, moderate and high (Fig. 7).

Based on these rules and corresponding contingency ranking membership value a area is selected in fuzzification. This area is further de-fuzzified which gives the fuzzy coefficient. The following rules are implemented to obtain the fuzzy coefficient for IEEE-14 bus system and a practical 75 bus Indian system (Table 2 and 3 ).

\section{PROCEDURAL STEPS FOR THE CONTINGENCY RANKING LIST}

The multi-criteria based contingency rank is prepared using the following flow chart. The additional performance indices of the entire system can be ranked as to generate rank lists.

The additional multi-criteria based ranking approach generally gives idea about the contingency planning in the deregulated environment. The flow chart shown in Fig. 8 shows the steps involved in preparing a contingency ranking list. 
Int. J. Soft Comput., 5 (4): 185-193, 2010

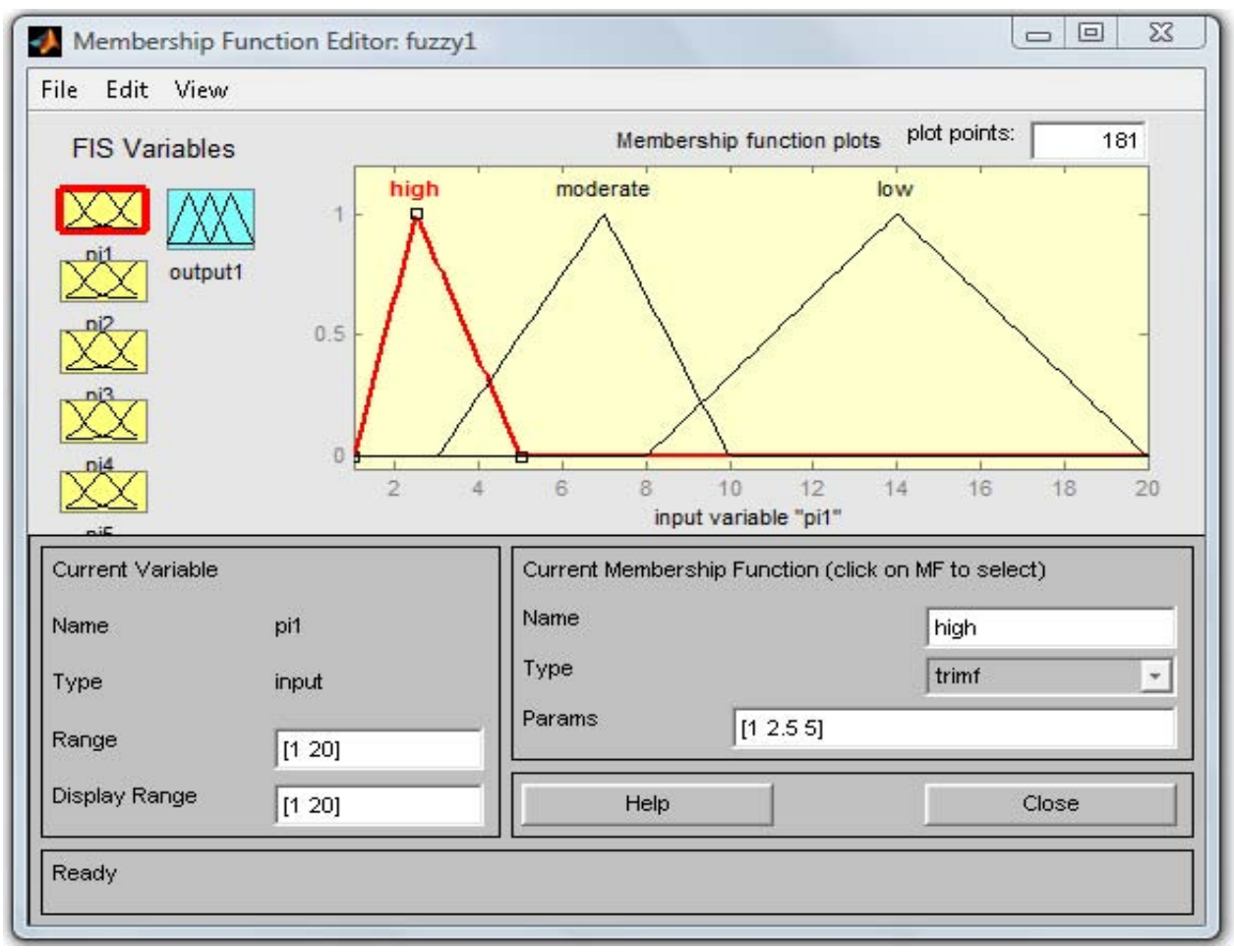

Fig. 6: Membership functions of the performance indices

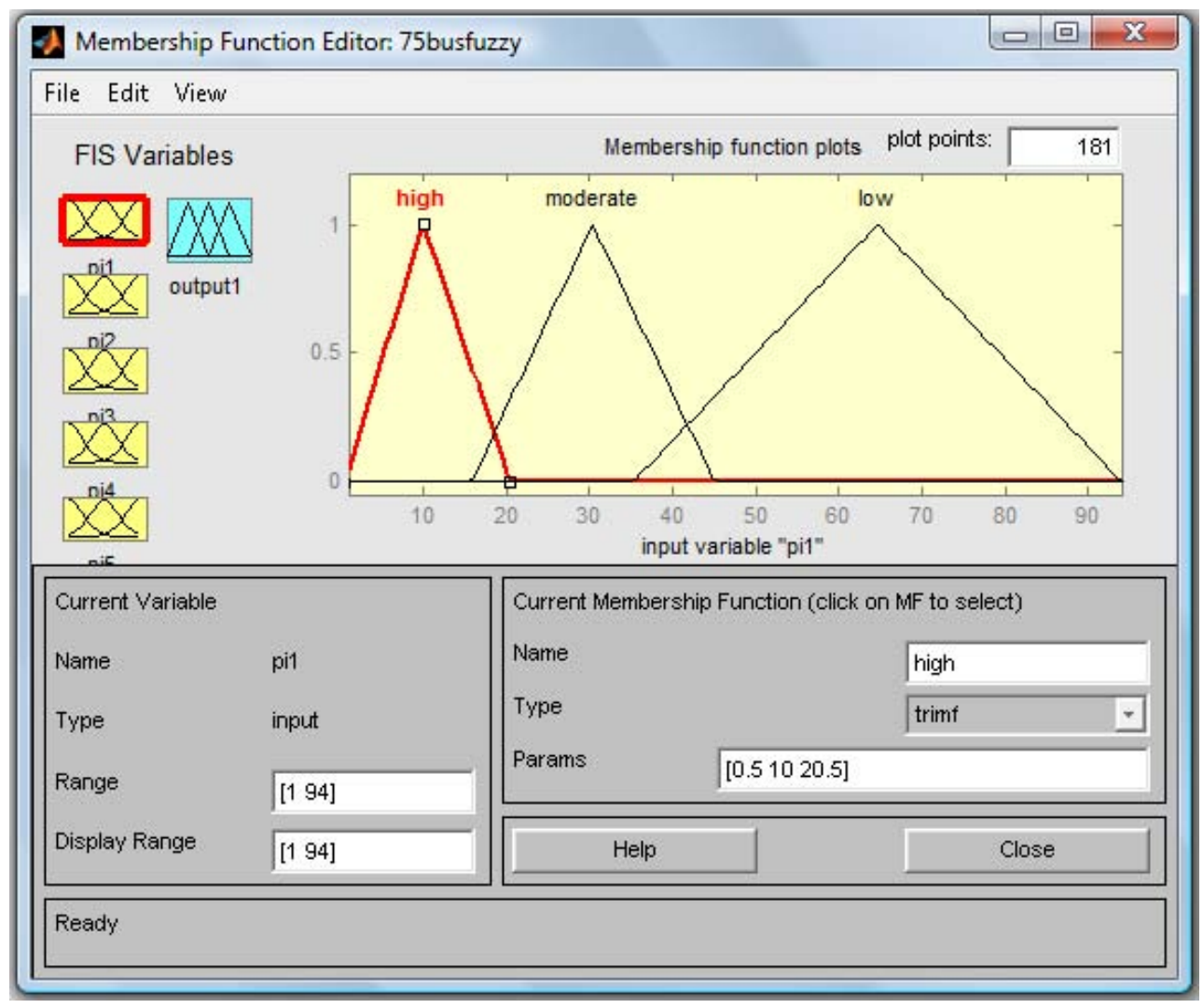

Fig. 7: Membership functions of the performance indices for practical indian 75 bus system 
Int. J. Soft Comput., 5 (4): 185-193, 2010

Table 2: Fuzzy membership values for practical Indian 75 bus system

\begin{tabular}{lrrrrrr}
\hline Values & \multicolumn{1}{c}{$\mathrm{PI}_{1}$} & \multicolumn{1}{c}{$\mathrm{PI}_{2}$} & \multicolumn{1}{c}{$\mathrm{PI}_{3}$} & \multicolumn{1}{c}{$\mathrm{PI}_{4}$} & \multicolumn{1}{c}{$\mathrm{PI}_{5}$} & $\begin{array}{c}\text { Fuzzy rank } \\
\text { coefficient }\end{array}$ \\
High & $1-20$ & $1-20$ & $1-20$ & $1-20$ & $1-20$ & $1-20$ \\
Moderate & $15-45$ & $15-45$ & $15-45$ & $15-45$ & $15-45$ & $15-45$ \\
Low & $35-98$ & $35-98$ & $35-98$ & $35-98$ & $35-98$ & $35-98$ \\
\hline
\end{tabular}

Table 3: Fuzzy rules for practical Indian 75 bus system

\begin{tabular}{|c|c|c|c|c|c|c|}
\hline $\begin{array}{l}\text { Rule } \\
\text { no }\end{array}$ & $\mathrm{PI}_{1}$ & $\mathrm{PI}_{2}$ & $\mathrm{PI}_{3}$ & $\mathrm{PI}_{4}$ & $\mathrm{PI}_{5}$ & $\begin{array}{c}\text { Fuzzy rank } \\
\text { coefficient }\end{array}$ \\
\hline 1 & High & High & High & High & High & High \\
\hline 2 & High & High & High & High & Moder & igh \\
\hline 2 & High & High & High & Moderate & High & figh \\
\hline . & High & High & High & Moderate & Moderate & High \\
\hline 5 & High & High & High & Low & Low & Moderate \\
\hline 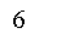 & High & Moderate & Moderate & Low & Low & Moderate \\
\hline 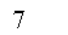 & High & Moderate & Low & Low & Low & Low \\
\hline 8 & Low & High & Moderate & Low & Low & Low \\
\hline . & Low & High & Moderate & Moderate & Moderate & Moderate \\
\hline 10 & Low & High & High & Moderate & High & High \\
\hline 11 & Low & High & High & High & High & High \\
\hline 12 & Low & High & High & Moderate & Moderate & Moderate \\
\hline 13 & Moderate & Moderate & High & Low & Low & Moderate \\
\hline 14 & Low & High & High & Moderate & High & High \\
\hline 15 & Low & Moderate & High & High & Moderate & Moderate \\
\hline 16 & Low & Moderate & High & Low & Moderate & Low \\
\hline$\underline{17}$ & Low & Low & Low & High & High & Moderate \\
\hline
\end{tabular}

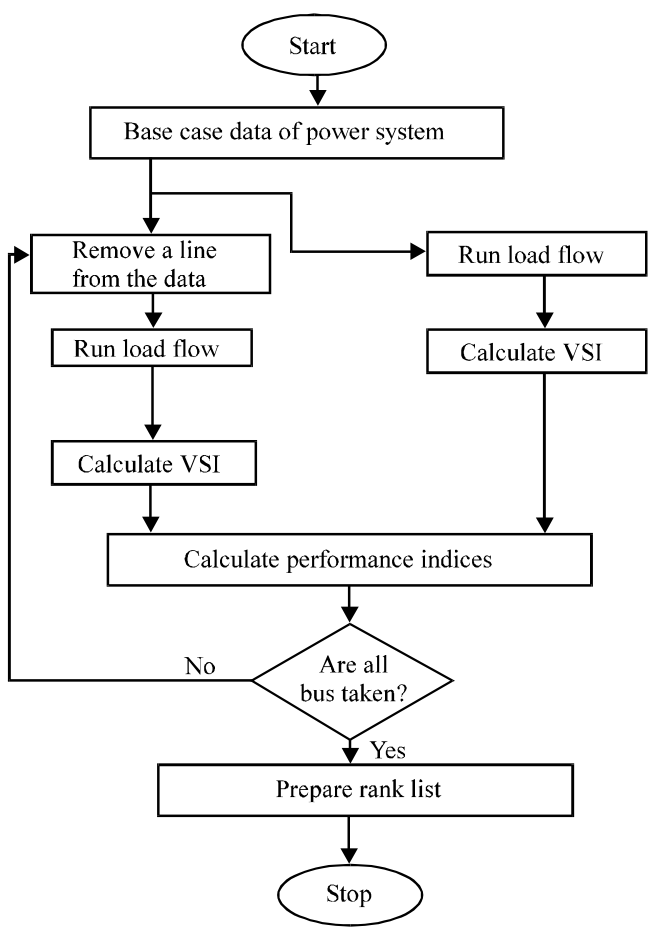

Fig. 8: Flow chart for fuzzy based multi criteria contingency ranking

\section{RESULTS AND DISCUSSION}

The proposed fuzzy inference system is tested on the IEEE-14 bus system and 75 bus practical Indian systems. Obtain the post-contingency (VSM) for each contingency
Table 4: Contingency ranking by loading parameter $(\lambda)$ for ieee 14 bus system

\begin{tabular}{lclr}
\hline Line no. & From-To & $\lambda_{\max }$ & Order \\
\hline 1 & $1-2$ & 0.97358 & 1 \\
3 & $2-3$ & 1.29430 & 2 \\
10 & $5-6$ & 1.29460 & 3 \\
2 & $1-5$ & 1.38580 & 4 \\
15 & $7-9$ & 1.44160 & 5 \\
4 & $2-4$ & 1.57500 & 6 \\
8 & $4-7$ & 1.56150 & 7 \\
7 & $4-5$ & 1.59300 & 8 \\
17 & $9-14$ & 1.60740 & 9 \\
5 & $2-5$ & 1.64350 & 10 \\
13 & $6-13$ & 1.64970 & 11 \\
14 & $7-8$ & 1.65850 & 12 \\
9 & $4-9$ & 1.66620 & 13 \\
6 & $3-4$ & 1.70220 & 14 \\
16 & $9-10$ & 1.71080 & 15 \\
12 & $6-12$ & 1.71780 & 16 \\
20 & $13-14$ & 1.72830 & 17 \\
11 & $6-11$ & 1.73110 & 18 \\
18 & $10-11$ & 1.74880 & 19 \\
19 & $12-13$ & 1.75000 & 20 \\
\hline
\end{tabular}

Table 5: Fuzzy membership values for ieee-14 bus system

\begin{tabular}{lrrrrrc}
\hline Values & $\mathrm{PI}_{1}$ & $\mathrm{PI}_{2}$ & \multicolumn{1}{c}{$\mathrm{PI}_{3}$} & $\mathrm{PI}_{4}$ & $\mathrm{PI}_{5}$ & $\begin{array}{c}\text { Fuzzy rank } \\
\text { coefficient }\end{array}$ \\
\hline High & $1-5$ & $1-5$ & $1-5$ & $1-5$ & $1-5$ & $1-5$ \\
Moderate & $3-10$ & $3-10$ & $3-10$ & $3-10$ & $3-10$ & $3-10$ \\
Low & $8-20$ & $8-20$ & $8-20$ & $8-20$ & $8-20$ & $8-20$ \\
\hline
\end{tabular}

of the list by using some known method as for example the continuation method or by successive load flow computations for gradually increasing load until load flow solutions are no longer found. The latter is of course very time consuming, however its results are acceptable from a practical point of view. The results were used as a reference in this study. Rank contingencies according to their VSM computed using Continuation power flow obtaining list N. Perform the multi criteria contingency ranking and obtain five ordered lists corresponding to the five PI's. Obtain list P which corresponds to the union of the five ordered lists (five PI's).

IEEE-14 bus system: For the sake of illustration, a detailed description of a simulation for the IEEE 14-bus, 20-branch system is shown. Table 4 shows the ranking of the ten most severe single contingencies. They were ranked according to the respective value of the loading factor as shown in Table 5. Note that MVAR limits at generation units have been enforced in all simulations shown here. The outage of branch 1 (connecting buses 1 and 2) results in an infeasible operating state and $\lambda_{\max }<1$ (negative VSM). On the other hand they may also result in small impact on the system's maximum loading. In fact, this is the usual case for realistic systems.

Table 4 shows the ranking of the twenty single contingencies. They were ranked according to the respective value of the loading parameter. The line 1(1-2) 
Int. J. Soft Comput., 5 (4): 185-193, 2010

Table 6: Performance indices of ieee 14 bus system for single line outage

\begin{tabular}{llrrrrcc} 
Line no & Branch & $\mathrm{VSI}_{\min }$ & \multicolumn{1}{c}{$\mathrm{PI}_{1}$} & \multicolumn{1}{c}{$\mathrm{PI}_{2}$} & \multicolumn{1}{c}{$\mathrm{PI}_{3}$} & $\mathrm{PI}_{4}$ & $\mathrm{PI}_{5}$ \\
\hline 1 & $1-2$ & 0 & 0.00 & 0.0000 & 0.000 & 2.1496 & 0.9178 \\
2 & $1-5$ & 12 & 3.97 & 87.7100 & 220.580 & 1.2794 & 0.4759 \\
3 & $2-3$ & 4 & 5.45 & 16.3100 & 27.970 & 1.0225 & 0.4217 \\
4 & $2-4$ & 4 & 7.10 & 40.9400 & 101.520 & 0.9491 & 0.3638 \\
5 & $2-5$ & 4 & 9.66 & 48.4200 & 138.880 & 0.7174 & 0.2660 \\
6 & $3-4$ & 5 & 21.15 & 20.7200 & 88.180 & 0.3981 & 0.1500 \\
7 & $4-5$ & 3 & 4.60 & 29.2700 & 53.480 & 1.0253 & 0.4462 \\
8 & $4-7$ & 1 & 32.46 & 44.2870 & 157.232 & 0.4818 & 0.2108 \\
9 & $4-9$ & 13 & 80.00 & 80.5900 & 170.820 & 0.2737 & 0.1089 \\
10 & $5-6$ & 1 & 22.66 & 42.3200 & 77.700 & 0.8600 & 0.2909 \\
11 & $6-11$ & 5 & 67.02 & 34.8600 & 67.290 & 0.1691 & 0.0581 \\
12 & $6-12$ & 5 & 61.95 & 34.8900 & 64.020 & 0.1758 & 0.0528 \\
13 & $6-13$ & 3 & 16.00 & 18.8200 & 21.770 & 4.4143 & 0.1151 \\
14 & $7-8$ & 0 & 0.00 & 0.0000 & 0.000 & 0.2851 & 0.1061 \\
15 & $7-9$ & 3 & 10.04 & 9.7847 & 16.170 & 0.6601 & 0.1831 \\
16 & $9-10$ & 5 & 68.49 & 66.3130 & 18.411 & 0.1466 & 0.0493 \\
17 & $9-14$ & 1 & 94.60 & 52.8541 & 56.243 & 0.2068 & 0.0787 \\
18 & $10-11$ & 5 & 145.77 & 181.8180 & 155.280 & 0.0780 & 0.0263 \\
19 & $12-13$ & 5 & 295.85 & 423.7300 & 409.836 & 0.0376 & 0.0120 \\
20 & $13-14$ & 5 & 292.25 & 63.3700 & 72.464 & 0.1243 & 0.0391 \\
\hline
\end{tabular}

Table 7: Contingency ranking for IEEE-14 bus system based on PI values

\begin{tabular}{llrrrrr} 
Line no & Branch & $\mathrm{PI}_{1}$ & \multicolumn{1}{c}{$\mathrm{PI}_{2}$} & $\mathrm{PI}_{3}$ & $\mathrm{PI}_{4}$ & \multicolumn{1}{c}{$\mathrm{PI}_{5}$} \\
\hline 1 & $1-2$ & 1 & 1 & 1 & 1 & 1 \\
2 & $1-5$ & 2 & 17 & 18 & 2 & 2 \\
3 & $2-3$ & 4 & 3 & 4 & 4 & 4 \\
4 & $2-4$ & 5 & 9 & 13 & 5 & 5 \\
5 & $2-5$ & 6 & 12 & 14 & 7 & 7 \\
6 & $3-4$ & 9 & 6 & 12 & 11 & 10 \\
7 & $4-5$ & 3 & 5 & 5 & 3 & 3 \\
8 & $4-7$ & 11 & 11 & 16 & 9 & 8 \\
9 & $4-9$ & 15 & 16 & 17 & 12 & 12 \\
10 & $5-6$ & 10 & 10 & 11 & 6 & 6 \\
11 & $6-11$ & 13 & 7 & 9 & 15 & 15 \\
12 & $6-12$ & 12 & 8 & 8 & 14 & 16 \\
13 & $6-13$ & 8 & 4 & 3 & 10 & 11 \\
14 & $7-8$ & 1 & - & - & - & - \\
15 & $7-9$ & 7 & 2 & 2 & 8 & 9 \\
16 & $9-10$ & 14 & 15 & 7 & 16 & 16 \\
17 & $9-14$ & 17 & 13 & 6 & 13 & 13 \\
18 & $10-11$ & 18 & 18 & 15 & 18 & 18 \\
19 & $12-13$ & 19 & 19 & 19 & 19 & 19 \\
20 & $13-14$ & 16 & 14 & 10 & 17 & 17 \\
\hline
\end{tabular}

have lowest value of $\lambda_{\max }$ that's why it is ranked no. 1 that means the outage of line 1 is most severe. Table 6 shows the performance indices and $\mathrm{VSI}_{\min }$ value for each contingency. The outage of line 1 and 14 gives negative value of VSI which shows infeasible case that's why its VSI value and respective PI value are made 0 . Table 7 shows the contingency ranking based on performance indices. The line outage for which the PI value is lowest (for first $3 \mathrm{PI}$ ) is ranked 1 i.e., most severe. Where as for last two the line which has highest PI value is ranked 1 as most severe. The line 1 has ranked no. 1 in all PI rankings which shows the outage of line 1 is most severe.

Using the fuzzy approach a fuzzy coefficient is generated by combining the five contingency rankings which is shown in Table 8 . The line outage whose fuzzy coefficient is lowest is ranked highest. Here also the line nol is ranked as most severe contingency which shows the effectiveness of this method.

\begin{tabular}{|c|c|c|c|}
\hline Line no & Branch no & Fuzzy coefficient & Rank \\
\hline 1 & $1-2$ & 2.91 & 01 \\
\hline 2 & $1-5$ & 2.92 & 03 \\
\hline 3 & $2-3$ & 2.91 & 02 \\
\hline 4 & $2-4$ & 6.54 & 07 \\
\hline 5 & $2-5$ & 6.58 & 08 \\
\hline 6 & $3-4$ & 6.58 & 09 \\
\hline 7 & $4-5$ & 3.02 & 05 \\
\hline 8 & $4-7$ & 7.23 & 11 \\
\hline 9 & $4-9$ & 6.51 & 06 \\
\hline 10 & $5-6$ & 14.00 & 12 \\
\hline 11 & $6-11$ & 14.00 & 13 \\
\hline 12 & $6-12$ & 6.57 & 10 \\
\hline 13 & $6-13$ & 3.00 & 04 \\
\hline 14 & $7-8$ & 14.00 & 14 \\
\hline 15 & $7-9$ & 14.00 & 15 \\
\hline 16 & $9-10$ & 14.00 & 16 \\
\hline 17 & $9-14$ & 14.00 & 17 \\
\hline 18 & $10-11$ & 14.00 & 18 \\
\hline 19 & $12-13$ & 14.00 & 19 \\
\hline 20 & $13-14$ & 14.00 & 20 \\
\hline
\end{tabular}

Table 9: Contingency ranking by loading parameter $(\lambda)$ for IEEE 14 bus system

\begin{tabular}{|c|c|c|c|c|c|}
\hline From-To & $\lambda_{\max }$ & Order & From-To & $\lambda_{\max }$ & Order \\
\hline $19-20$ & 0 & 1 & $38-29$ & 1.1395 & 48 \\
\hline $41-12$ & 0 & 2 & $74-41$ & 1.1352 & 49 \\
\hline $16-02$ & $1 * 10^{-5}$ & 3 & $38-22$ & 1.1454 & 50 \\
\hline $18-03$ & $1^{*} 10^{-5}$ & 4 & $17-16$ & 1.1457 & 51 \\
\hline $31-05$ & 0.0001 & 5 & $29-22$ & 1.1498 & 52 \\
\hline $32-06$ & 0.0001 & 6 & $19-36$ & 1.1501 & 53 \\
\hline 33-07 & 0.0001 & 7 & $31-32$ & 1.5140 & 54 \\
\hline 34-08 & 0.0001 & 8 & $59-39$ & 1.1542 & 55 \\
\hline $35-09$ & 0.0001 & 9 & $17-35$ & 1.1570 & 56 \\
\hline $36-37$ & 0.0001 & 10 & $54-28$ & 1.1575 & 57 \\
\hline $42-13$ & 0.0001 & 11 & $30-57$ & 1.1582 & 58 \\
\hline $43-14$ & 0.0001 & 12 & $43-58$ & 1.1592 & 59 \\
\hline $44-15$ & 0.0001 & 13 & $28-56$ & 1.1601 & 60 \\
\hline $28-04$ & 0.0001 & 14 & $47-67$ & 1.1608 & 61 \\
\hline $24-10$ & 0.0002 & 15 & $53-30$ & 1.1608 & 62 \\
\hline $40-11$ & 0.0002 & 16 & $25-43$ & 1.1610 & 63 \\
\hline $20-64$ & 0.0002 & 17 & $56-30$ & 1.1610 & 64 \\
\hline $51-52$ & 0.0002 & 18 & $22-25$ & 1.1615 & 65 \\
\hline $25-60$ & 0.0002 & 19 & $24-27$ & 1.1616 & 66 \\
\hline $20-66$ & 0.0002 & 20 & $38-39$ & 1.1622 & 67 \\
\hline $37-69$ & 0.0002 & 21 & $30-65$ & 1.1624 & 68 \\
\hline $70-72$ & 0.0002 & 22 & $18-68$ & 1.1625 & 69 \\
\hline $17-01$ & 0.035 & 23 & $18-71$ & 1.1625 & 70 \\
\hline $25-72$ & 0.035 & 24 & $57-58$ & 1.1629 & 71 \\
\hline $34-54$ & 0.035 & 25 & $40-48$ & 1.1632 & 72 \\
\hline $27-51$ & 0.035 & 26 & $30-61$ & 1.1634 & 73 \\
\hline $29-75$ & 1.0386 & 27 & $43-56$ & 1.1634 & 74 \\
\hline $55-44$ & 1.0547 & 28 & $49-40$ & 1.1634 & 75 \\
\hline $74-73$ & 1.0576 & 29 & $61-62$ & 1.1636 & 76 \\
\hline $23-29$ & 1.0652 & 30 & $39-31$ & 1.1641 & 77 \\
\hline $73-45$ & 1.0859 & 31 & $39-31$ & 1.1641 & 78 \\
\hline $26-22$ & 1.0889 & 32 & $27-68$ & 1.1642 & 79 \\
\hline $16-50$ & 1.0922 & 33 & $35-41$ & 1.1647 & 80 \\
\hline $45-44$ & 1.1022 & 34 & $28-55$ & 1.1648 & 81 \\
\hline $24-54$ & 1.1075 & 35 & $55-63$ & 1.1650 & 82 \\
\hline $19-26$ & 1.1091 & 36 & $46-37$ & 1.1653 & 83 \\
\hline $16-46$ & 1.1096 & 37 & $18-47$ & 1.1653 & 84 \\
\hline $23-74$ & 1.1113 & 38 & $21-30$ & 1.1660 & 85 \\
\hline $74-41$ & 1.1123 & 39 & $48-49$ & 1.1661 & 86 \\
\hline $17-23$ & 1.1126 & 40 & $53-61$ & 1.1664 & 87 \\
\hline $42-74$ & 1.1134 & 41 & $57-59$ & 1.1665 & 88 \\
\hline $41-42$ & 1.1135 & 42 & $27-71$ & 1.1667 & 89 \\
\hline $26-41$ & 1.1215 & 43 & $21-65$ & 1.1667 & 90 \\
\hline $29-30$ & 1.2266 & 44 & $54-63$ & 1.1670 & 91 \\
\hline $23-24$ & 1.2747 & 45 & $24-67$ & 1.1672 & 92 \\
\hline $26-27$ & 1.2797 & 46 & $28-43$ & 1.1678 & 93 \\
\hline$\underline{35-36}$ & 1.1259 & 47 & & & \\
\hline
\end{tabular}


Table 10: Contingency ranking for indian utility 75 bus system based on PI values. Fiures in parenthesis shows the line connection i.e., from one bus to other bus

\begin{tabular}{lrrrrc}
\hline Order & \multicolumn{1}{c}{ PI1 } & \multicolumn{1}{c}{ PI2 } & \multicolumn{1}{c}{ PI3 } & PI4 & PI5 \\
\hline 1 & $64(20-40)$ & $1(19-20)$ & $1(19-20)$ & $48(53-61)$ & $48(53-61)$ \\
2 & $1(19-20)$ & $64(20-40)$ & $64(20-40)$ & $51(57-59)$ & $51(57-59)$ \\
3 & $16(36-37)$ & $16(36-37)$ & $16(36-37)$ & $45(56-30)$ & $45(56-30)$ \\
4 & $58(32-62)$ & $58(32-62)$ & $75(29-75)$ & $86(27-71)$ & $95(70-72)$ \\
5 & $20(41-12)$ & $11(31-05)$ & $80(20-66)$ & $95(70-72)$ & $80(20-66$ \\
6 & $21(42-13)$ & $12(32-06)$ & $30(20-64)$ & $56(55-63)$ & $86(27-71)$ \\
7 & $10(29-30)$ & $39(25-60)$ & $41(34-54)$ & $72(48-49)$ & $56(55-63)$ \\
8 & $6(22-25)$ & $94(37-69)$ & $39(25-60)$ & $41(34-54)$ & $72(48-49)$ \\
9 & $91(55-44)$ & $80(20-66)$ & $37(27-51)$ & $80(20-66)$ & $53(39-31)$ \\
10 & $15(35-09)$ & $35(24-27)$ & $35(24-27)$ & $53(39-31)$ & $30(20-64)$ \\
11 & $81(23-74)$ & $30(20-64)$ & $95(70-72)$ & $55(54-63)$ & $55(54-63)$ \\
12 & $27(17-19)$ & $9(28-04)$ & $94(37-69)$ & $70(29-22)$ & $70(29-22)$ \\
13 & $78(41-42)$ & $2(16-02)$ & $54(39-33)$ & $96(21-65)$ & $96(21-65)$ \\
14 & $8(26-27)$ & $14(34-08)$ & $25(16-46)$ & $97(21-30)$ & $97(21-30)$ \\
15 & $67(74-41)$ & $15(35-09)$ & $25(62-32)$ & $82(24-67)$ & $94(37-69)$ \\
\hline
\end{tabular}

Table 11: Fuzzy based contingency ranking for Indian utility 75 bus system

\begin{tabular}{|c|c|c|c|}
\hline Branch no & Line no & Fuzzy coefficient & Rank \\
\hline $20-40$ & 64 & 2.90 & 1 \\
\hline $19-20$ & 1 & 10.50 & 24 \\
\hline $36-37$ & 16 & 2.92 & 3 \\
\hline $62-32$ & 58 & 2.95 & 4 \\
\hline $41-12$ & 20 & 6.53 & 13 \\
\hline $42-13$ & 21 & 6.53 & 14 \\
\hline $29-30$ & 10 & 9.16 & 23 \\
\hline $22-25$ & 6 & 6.53 & 15 \\
\hline $55-44$ & 91 & 6.57 & 16 \\
\hline $31-05$ & 11 & 6.61 & 20 \\
\hline $32-06$ & 12 & 6.59 & 19 \\
\hline $25-60$ & 39 & 3.89 & 11 \\
\hline $37-69$ & 94 & 2.90 & 2 \\
\hline $20-66$ & 80 & 6.58 & 18 \\
\hline $24-27$ & 35 & 6.57 & 17 \\
\hline $29-75$ & 93 & 3.08 & 10 \\
\hline $20-64$ & 30 & 6.61 & 21 \\
\hline $34-54$ & 41 & 14.00 & 25 \\
\hline $27-51$ & 37 & 2.99 & 7 \\
\hline $53-61$ & 48 & 3.01 & 9 \\
\hline $57-59$ & 51 & 3.00 & 8 \\
\hline $56-30$ & 45 & 4.57 & 12 \\
\hline $70-72$ & 95 & 2.96 & 6 \\
\hline $27-71$ & 86 & 2.95 & 5 \\
\hline $55-63$ & 56 & 6.90 & 22 \\
\hline
\end{tabular}

Practical 75 bus Indian system: Practical Indian 75 -Bus System having 15 generators including one slack bus, 60 load buses and 24 transformers lines. The Table 9 shows the ranking of the single contingencies. They were ranked according to the respective value of the loading parameter. The line 1 (19-20) have lowest value of $\lambda_{\max }$ that's why it is ranked no. 1 that means the outage of line 1 is most severe.

Table 10 shows the contingency ranking based on performance indices. The line outage for which the PI value is lowest (for first $3 \mathrm{PI}$ ) is ranked 1 i.e., most severe. Where as for last two the line which has highest PI value is ranked 1 as most severe.

Using the fuzzy approach a fuzzy coefficient is generated by combining the five contingency rankings which is shown in Table 11. The line outage whose fuzzy coefficient is lowest is ranked highest. Here line no. 64 has minimum fuzzy coefficient which shows this is the most severe contingency of this system.

\section{CONCLUSION}

The contingency ranking method for voltage stability applied in this project shows a great potential to be used as a tool for real time operation. This project demonstrated that various performance indices couldn't reliably capture all the instable cases individually.

Each index can't rank the severity of contingency for different system under different conditions but the combination of indices can give an overall evaluation from different aspects of the system. Results on two test systems showed that combination of indices CI with use of fuzzy will provide a better ranking for worst cases.

As evidenced by the results of IEEE 14 bus system and a practical Indian 75 bus system the approach used can provide the user with those outages that may cause immediate loss of load or islanding at a certain bus. This is a kind of information which is very helpful to system operators.

An overall severity index is given for which outage case. These severity indices can be used as a guideline for deciding whether corrective control actions should be taken.

\section{ACKNOWLEDGEMENT}

The researchers would like to thank the management and faculty of VIT University for their kind support and encouragement throughout this research.

\section{REFERENCES}

Ajjarapu, V. and C. Christy, 1992. The continuation power flow: A tool to study steady state voltage stability. IEEE Trans. Power Syst., 7: 416-423.

Albuquerque, M.A. and C.A. Castro, 2003. A contingency ranking method for voltage stability in real time operation of power systems. Proceedings of the IEEE Bologna Power Tech Conference, June 23-26, Bologna, Italy, PP: 5-5.

Hsu, Y.Y. and H.C. Kuo, 1992. Fuzzy set based contingency ranking. IEEE Trans. Power Syst., 7: 1189-1196. 
Lo, K.L. and A.K. Abdelall, 2000. Fuzzy logic based contingency analysis. Proceedings of the IEEE International Conference on Electric Utility Deregulation and Restructuring and Power Technologies, April 4-7, London, UK., pp: 499-504.

Morison, K., L. Wang and P. Kundur, 2004. Power system security assessment. IEEE Power Energy Magaz., 2: $30-39$.
Ozdemir A. and C. Singh, 2001. Fuzzy logic based MW contingency ranking against masking problem. Proceedings of the IEEE Power Engineering Society Winter Meeting, Jan. 28, Columbus, OH, USA., pp: 504-509.

Stott, B., O. Alsac and A.J. Monticelli, 1987. Security analysis and optimization. EEEE Proc., 75: 1623-1644. 